\title{
Challenges in developing effective policy for soil carbon sequestration: perspectives on additionality, leakage, and permanence
}

\author{
Tas Thamo and David J. Pannell \\ Centre for Environmental Economics \& Policy, School of Agricultural \& Resource \\ Economics (M089), University of Western Australia, Crawley, Western Australia 6009
}

\begin{abstract}
If carbon sequestration is to be cost-effective substitute for reducing emissions then it must occur under a framework that ensures that the sequestration is additional to what would otherwise have occurred, the carbon is stored permanently, and any leakage is properly accounted for. We discuss significant challenges in meeting these requirements, including some not previously recognised. Although we focus on sequestration in soil, many of the issues covered are applicable to all types of sequestration. The common-practice method for determining additionality achieves its intention of reducing transaction costs in the short term but not in the medium-long term. Its design results in the least costly, additional abatement measures being excluded from policy support and fails to address how, in the case of sequestration, revisions to the additionality of sequestering practices should apply not just to the future, but in theory, also retrospectively. Permanence is sometimes approximated as 100 years of sequestration. Re-release of sequestered carbon after this will not only reverse the sequestration, but may raise atmospheric carbon to higher levels than they would have been if the sequestration had never occurred. Leakage associated with sequestration practices can accumulate over time to exceed the total level of sequestration; nonetheless adoption of such
\end{abstract}


practices can be attractive to landholders, even when they are required to pay for this leakage at contemporary prices.

Policy Relevance: Globally much has been written and claimed about the ability to offset emissions with sequestration. The Australian Government plans to use sequestration to source much of the abatement required to reach its emissions targets. Designing effective policy for sequestration will be challenging politically, and will involve substantial transaction costs. Compromises in policy design intended to make sequestration attractive and reduce transaction costs can render it highly inefficient as a policy.

Keywords: additionality, sequestration, carbon credits, climate change mitigation, climate policy frameworks, environmental economics

\section{Introduction}

Much has been written about the potential to offset greenhouse gas (GHG) emissions by sequestering carbon (e.g., García-Oliva \& Masera, 2004; Lal, 2002; Subak, 2000). To be effective, sequestration policies need to: encourage sequestration that is 'additional' to what would occur in the normal course of business (Meyers, 1999; Woodhams et al., 2012); avoid 'leaking’ or transferring emissions to another location, time, or form (e.g., Cowie, Eckard, \& Eady, 2012; van Kooten \& de Vries, 2013); and ensure that carbon is stored 'permanently’(McCarl, 2006; Murray, Sohngen, \& Ross, 2007) and not undone in the future without being replaced with other abatement. 
Various authors have identified and analysed challenges in meeting these three requirements. For example, Montserrat and Sohngen (2009) estimated that in some voluntary offset schemes, up to $90 \%$ of the claimed emissions 'savings' may have been shifted or 'leaked' to another location. Gustavsson et al., (2000) articulated how additionality is an inherently uncertain concept due to its dependence on an unobservable counterfactual scenario, lamenting that the buyers and sellers of offsets share a common motive to exploit such ambiguity and overestimate abatement, meaning sound regulatory oversight is an imperative. Murray et al. (2007) considered the feasibility of different policy designs for dealing with permanence. Others have warned that implementing policies that overvalue temporary sequestration relative to permanent abatement may be (politically) convenient, but ultimately inefficient (Feng, Zhao, \& Kling, 2002; Gramig, 2012).

A common theme in the literature is that satisfying requirements for additionality, nonleakage and, to a lesser degree, permanence increases transaction costs. These may be reduced by simplifying the policy, but at the cost of increased levels of uncertainty and reduced efficiency of the program (Cacho, Lipper, \& Moss, 2013; Capon, Harris, \& Reeson, 2013; Cowie et al., 2012; Subak, 2000).

With this paper we aim to: i) elucidate major issues around additionality, leakage, and permanence in the design of policy for sequestration of soil carbon, in the context of transaction costs and uncertainty; ii) identify potential perverse outcomes and inefficiencies in some of the policy approaches that have been proposed; and iii) consider the policy implications of our findings. Our study builds on the existing literature, extending it by focusing on issues that have not previously been emphasised, or in some cases, not previously recognised. These issues include that practices may be additional temporarily and yet not 
worth supporting in the short term; that practices can ultimately leak more emissions than they sequester and yet still be financially attractive to landholders; and that the use of a 100year rule (or similar) as a proxy for permanence can lead to atmospheric carbon levels being higher than they would have been in the absence of a sequestration policy.

We focus on carbon sequestration in soils — when we use the term 'sequestration' we are referring to soil carbon—although many of the issues we identify are relevant to other forms of carbon sequestration and to the design of any future policies throughout the world that aim to encourage sequestration, be it in soil or in vegetation. As a policy example we use the Carbon Farming Initiative (CFI) introduced by the Australian Government in late 2011 and modified in 2014. Thus far, only a modest amount of abatement has been generated by the CFI (as of December 2014, 10.6 Mt of $\mathrm{CO}_{2} \mathrm{e}$ ), much of it from landfill gas projects that were instigated under previous state-based schemes (Climate Change Authority, 2014a) and currently no projects involving soil carbon have been implemented. However, a new Australian Government was elected in September 2013 with the stated intent of sourcing the majority of the Australia's future abatement from an expanded CFI. As recently as June 2014, the Government was aspiring to achieve over three-quarters of this abatement by storing carbon on farms (Neales, 2014). We will at times also refer to the only existing offset credit scheme in which soil carbon has played a major role: Alberta’s Specified Greenhouse Gas Emitters Regulation (Climate Change Authority, 2014b). In this Canadian scheme 38\% of credits generated have been from carbon sequestered by the use of use minimum- or no-till cropping practices (Swallow \& Goddard, 2013).

This paper proceeds as follows. The next section considers potential policy approaches to, and dynamics of, carbon sequestration. Following this we consider different approaches for 
assessing additionality and the implications of its evolution through time. The risks created by the impermanent nature of carbon sequestration are then examined and the possible policy approaches for dealing with sequestration and leakage that occur over different timeframes are explored. We then reflect on the potential role of sequestration as part of a broader emissions mitigation strategy before summarising our findings.

\section{Carbon sequestration: dynamics, policy approaches and concepts}

\subsection{Sequestration in Soil}

Globally, the total amount of carbon stored in the top metre of soil (organic and inorganic pools) is estimated to be three times as much as the atmosphere and nearly four times as much as contained in living matter (Lal, 2002). However, with the expansion of agriculture, the carbon content of many soils has declined. It is estimated that in some regions up to $70 \%$ of these losses could be re-sequestered through improved land use or land management (Lal, 2002). For instance ‘no-tillage’ cultivation practices could increase soil carbon by about $16 \%$ worldwide (West \& Post, 2002). For mixed cropping-livestock farms in Western Australia, increasing the portion of legume pastures from $30 \%$ of farmed area to $80 \%$ would sequester 6t of $\mathrm{CO}_{2}$ /ha across the entire farmed area over 30 years (Kragt, Pannell, Robertson, \& Thamo, 2012). The amount of carbon sequestered when a new management practice is adopted depends on the initial carbon content, the practice, soil type and climate (Johnson, Levine, \& Kern, 1995; West et al., 2004). 
As a mitigation activity, sequestration has two unique characteristics. First, when a sequestering practice is adopted, carbon storage typically increases ${ }^{1}$, but at a diminishing rate through time until it plateaus at a new steady-state equilibrium (Figure 1) (Gramig, 2012; Hoyle, D’Antuono, Overheu, \& Murphy, 2013; West et al., 2004). Consequently, only a finite amount of sequestration is possible. Furthermore, this finite opportunity can only be exploited once; the same management practice implemented at a later date will ultimately sequester the same amount of carbon (Figure 1). Second, sequestration is reversible. To retain stored carbon the sequestering (or an equivalent) practice must be continued; reverting to the previous practice re-emits the carbon. Importantly, these two characteristics are not shared by strategies that reduce emissions (i.e., that prevent GHGs from entering the atmosphere, as opposed to sequestration which instead removes $\mathrm{CO}_{2}$ from the air). For this and other reasons, sequestration creates some particular challenges for policy design.

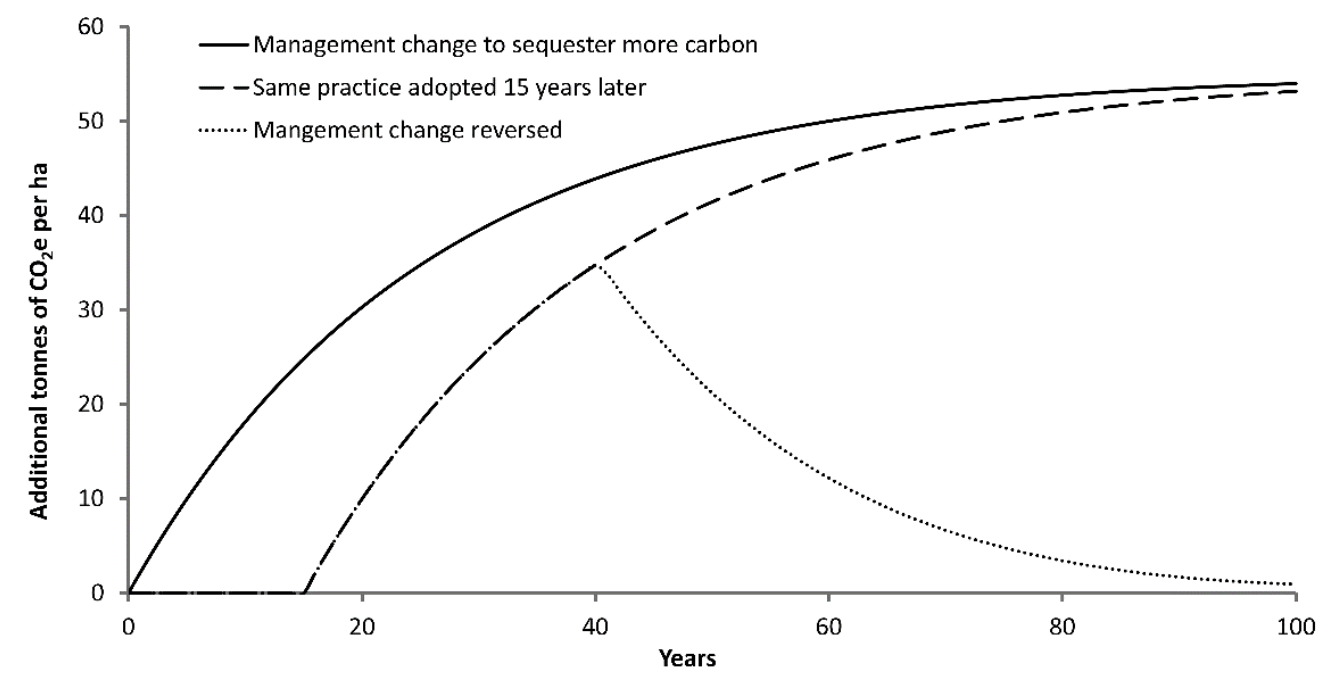

Figure 1. Stylised dynamics of carbon sequestration.

\footnotetext{
${ }^{1}$ Management changes can have a positive net effect on soil carbon levels in two ways: i) by bringing about absolute increases in soil carbon; ii) by preventing a decline in soil carbon that would otherwise occur had the business-as-usual practice continued. Although in this article we primarily focus on the first effect, many of the issues we raise also apply to the second, because in both cases the mitigation is typically finite, reversible, and occurs at a diminishing rate through time.
} 


\subsection{Potential policy approaches}

Sequestering additional carbon to that which is optimal in the absence of a policy comes at an opportunity cost to farmers and so requires incentivisation ${ }^{2}$. One way to incentivise sequestration is to incorporate it within a comprehensive emissions trading or carbon tax scheme. In the original CFI, landholders could claim credits for additional carbon sequestration (subject to regulatory approval) and sell them to polluters who could use these credits to offset their liabilities to the Australian Government's then implemented carbon tax. After revisions to the policy in 2014, landholders can participate in a reverse auction and receive payment from the government if their bid is judged to provide sufficiently good value for money. In the United States, since the failure of “cap and trade” legislation there has been increased interest in more traditional payment-based approaches to climate policy (e.g., Jones, Nickerson, \& Heisey, 2013; Lewandrowski \& Zook, 2015; Murray, 2015). In either of these approaches (reverse auction or direct payment), payments might be made for estimates of sequestration, or just for the adoption of practices that are believed to sequester carbon (Cowie et al., 2012; Subak, 2000).

We now look at three concepts that are central to the design and implementation of an efficient policy for carbon sequestration: additionality, permanence and leakage.

\subsection{Concepts: additionality, permanence and leakage}

For voluntary sequestration programs to work efficiently, whether they are offset- or payment-based, credits or incentives should only be provided for sequestration that is 'additional'. In other words, the aim of the policy is to increase sequestering projects that "result in abatement that would not have occurred in the absence of the [policy]. There would

\footnotetext{
${ }^{2}$ Sequestration practices may be financially attractive but still not adopted due to social or cultural factors (Pannell et al., 2006). Even though there may not be a financial opportunity cost in such a situation, incentivisation of some type will still likely be required to prompt practice change.
} 
be no reduction in emissions as a result of the [policy] if the project activity would have occurred in the normal course of business” (DCCEE, 2010, p.9). Inadequate assessment of additionality is a common flaw in carbon sequestration schemes (Trexler, 2011).

As carbon dioxide $\left(\mathrm{CO}_{2}\right)$ emissions reside in the atmosphere for $300+$ years ${ }^{3}$ (Archer, 2005), carbon sequestration must be enduring if it is to offset them. Consequently, to be effective, policies need to ensure the 'permanence' of sequestration.

'Leakage' refers to GHG emissions that occur as a result of activities undertaken to mitigate or offset GHG emissions. The degree of leakage needs to be quantified and set against the benefits of an activity when its eligibility for payments is considered. The leakage from sequestering $\mathrm{CO}_{2}$ may occur in another location, time, and/or form of GHG.

\section{Additionality}

When assessing additionality the following questions need to be addressed.

a) Is the sequestering practice additional?

b) If so, what is the 'benchmark' farming practice that it would displace?

c) How much of the abatement resulting from the new practice is additional?

Much of the discussion about additionality is focused on identifying a) and b) (e.g., Woodhams et al., 2012). However point c) is equally challenging. It requires determination of the net level of sequestration (i.e., also accounting for leakage) for both the sequestering

\footnotetext{
${ }^{3} 300$ years captures the atmospheric lifetime of the majority of the $\mathrm{CO}_{2}$ from an emissions pulse; in reality, the atmospheric lifetime of a $\mathrm{CO}_{2}$ emission is best represented by a decay function with an immensely 'long tail', such that it continues to influence climate at a diminishing rate for millennia (Archer, 2005; Eby et al., 2009).
} 
practice and the alternative it displaces. The requirement to answer question c) means that the measurement and monitoring (and associated transaction costs) that are often considered onerous for the sequestering activity, are also required for the benchmark. Furthermore, c) can vary in space and time even if a) and b) are unchanged.

\subsection{Approaches to determining additionality}

The economics of land uses are highly heterogeneous between (and even within) farms and over time. In principle, identification of the benchmark farming strategy and estimation of the opportunity cost of the sequestering practice might be done on a farm-by-farm basis using detailed bioeconomic models. In practice, this would have high transaction costs and would be hampered by poor information about each farm and each farmer's perceptions and preferences. Farm-by-farm modelling is not employed in the CFI because of concerns that the costs would discourage landholder participation (DCCEE, 2010). A streamlined approach could potentially involve modelling for groups of farmers, by industry, by region or potentially by other factors. Whether the greater inaccuracy introduced by this approach would outweigh the savings in transaction costs would depend on the heterogeneity of farms and the process used to aggregate them (e.g., Antle, Capalbo, Mooney, Elliott, \& Paustian, 2003; Capon et al., 2013). Regardless of if farms are modelled individually or in groups, economic models of farm businesses depend on subjective judgements about parameters and farmers’ objectives (Robertson, Pannell, \& Chalak, 2012), and ultimately their results are indicative of 'financial' additionality, whereas the question is really one of 'behavioural' additionality (Meyers, 1999). Although economic motivations are important to most commercial farmers, their behaviour in terms of adoption of new or different practices is also influenced by a broad suite of social, cultural and personal factors (Pannell et al., 2006). 
Reasonably accurate determination of additionality would require consideration of both financial and social factors. This would no doubt increase transaction costs further.

An alternative approach for assessing additionality (with lower transaction costs) is the method used in the original CFI: using empirical survey data to determine whether a practice is common in a district. If, in the absence of a sequestration policy, a practice is undertaken by 5 to $20 \%$ or less of potential adopters it is treated as being additional (Woodhams et al., 2012).

This ‘common-practice’ approach to determing additionality has several limitiations. Firstly, it is subjective. The critical threshold of 5\% adoption was choosen in the CFI because it approximates the 'take-off' point on a sigmoid-shaped adoption curve (Woodhams et al., 2012). However, it is not clear why this 'take-off' point is logically linked to additionality. It is essentially an arbitrary value.

Secondly, there is the issue of the scale-of-adoption or frequency-of-adoption. The commonpractice approach treats adoption as a binary yes/no question. It ignores the possibility that farmers who have already adopted a sequestering practice on a small scale (or at a certain frequency) may like to respond to the policy by increasing their scale (or frequency) of adoption. For example, suppose that $30 \%$ of farmers have adopted a sequestering practice (exceeding the threshold for additionality) but each has adopted it on only 5\% of their land. If they were eligible to participate in the sequestration program, they would adopt the practice on $50 \%$ of their land. The extra $45 \%$ adoption would be consistent with additionality, but would be ineligible with the common-practice approach. 
The ineligibility of increased scale or frequency of adoption is concerning because it is likely to provide sequestration at relatively low cost. Practices rare in a district probably have higher marginal costs of adoption than ones already practised in parts of the district. And a practice that is already adopted on part of a farm is likely to have a very low marginal cost of increased adoption. This highlights an irony. Abatement practices with a low opportunity cost (the so-called 'low-hanging fruit') are more likely to be viable in their own right, making assessment of their additionality difficult and costly. Once these more expensive implementation and transactions costs are considered, the actual cost of utilising such abatement in a sequestration policy may be much higher (Fosci, 2013). Conversely those practices whose additionality is more easily determined are also likely to require larger incentives to be adopted. It is the latter practices that the common-practice approach seems more suited to.

A third limitation of the common-practice approach is that its main benefit-reducing the amount of costly analysis required to determine additionality-is only temporary. Once the program is in place, a new challenge emerges: estimating what the level of adoption would have been in the absence of the program. This information is required to ensure that practices that are common only because of the scheme, and which are therefore genuinely additional, remain eligible. However, if regulators are able to identify and quantify which instances of observed adoption are non-additional, then in principle there is no need to adopt the commonpractice approach. Thus, reductions in transaction costs with the simplified common-practice approach will be short-lived. Either costly new research and analysis will be required to continue the program, or the accuracy of judgements about additionality will fall over time. 
Fourthly, if it is judged that in the absence of the program, the level of adoption would fall below the specified threshold, then under the common-practice approach, all farmers who adopt the practice would be eligible to claim benefits in the program. Some of those claims will be for non-additional adoption, including all the adoption that occurred prior to commencement of the scheme. Conversely, once practices do exceed the threshold level of adoption and become ineligible, they are disqualified for all landholders, including those for whom adoption would have been genuinely additional. This results in a lesser supply of sequestration than would occur in an ideal program. To reduce these issues, Woodhams et al. (2012) proposed scaling estimates of sequestration down by the proportion of it adjudged to be non-additional, creating an 'integrity buffer' (McCarl (2006) proposed 'additionality discounting' based on a similar concept). Using this approach, a portion of the sequestration by a practice could remain 'additional', even though the practice is commonly-adopted overall.

Although this scaling approach appears attractive, it too has issues. Determining the appropriate amount of scaling requires regulators to do what they were trying to avoid: determine how much of the observed adoption is additional to what would have happened in an unobservable, counterfactual scenario. It is arguably also unjust. Farmers adopting a practice in response to the sequestration policy would have the amount of sequestration they could claim reduced, to subsidise the claiming of non-additional sequestration by those who had (or would have) adopted the practice without the policy. Lastly, scaling to compensate for abatement that is 'lower quality' (non-additional or otherwise) could also potentially be self-fulfilling, in that it could lower the quality of the abatement portfolio even more. By reducing the amount of income received for a sequestering practice, scaling reduces the incentive to undertake that practice. This is important. As incentives to adopt a practice 
decrease, the proportion of total adoption of that practice that is additional will decrease (Claassen, Horowitz, Duquette, \& Ueda, 2014). Suppose after scaling a landholder can earn only \$5 for every hectare they undertake of a sequestering practice. This is most likely insufficient to induce many landholders to change practice, so nearly all those undertaking the practice and therefore eligible for the $\$ 5 /$ ha would be those doing the practice anyway.

The Alberta scheme also uses a common-practice-type approach to additionality, with a threshold level of $40 \%$ adoption, and a scaled baseline, similar in nature to the 'integrity buffer’ (Woodhams et al., 2012) and ‘additionality discounting' (McCarl, 2006) concepts. When the scheme commenced in 2007, landholders already practicing reduced tillage were eligible to claim credits for the amount they were estimated to have sequestered over the previous five years. The justification for including non-additional adoption was that it created an incentive for landholders to maintain sequestration that could otherwise have been rereleased (Government of Alberta, 2012). After claiming these initial credits, many smaller landholders are reported to have ceased involvement in the scheme because they felt it was not cost-effective (Climate Change Authority, 2014b). These landholders who ceased participating must have either: a) continued to practise reduced tillage but just not partaken in the scheme, as might occur if income from the offset scheme did not justify the transaction costs and the effort involved with participating in it, suggesting non-additionality or; b) also ceased practising reduced tillage, as might occur if income from the offset scheme was insufficient to cover the opportunity cost of altering tillage practices, in which case sequestration would be re-released.

Overall, there are serious limitations with the common-practice approach to determining additionality. Some (but not all) of those problems could be addressed by using good 
information about additionality, but if that information is available, the common-practice approach is not needed.

There are also some challenging aspects inherent to all approaches for assessing additionality. First, additionality must be assessed against a counterfactual benchmark situation that cannot be observed: the farming practices that would have been employed if the policy had never existed. As time passed following adoption of the sequestering activity, judgements about the unobserved benchmark would become increasingly difficult and speculative (Murray et al., 2007). Such uncertainty makes the determination of additionality potentially susceptible to political manipulation. Second, sequestration is a long process. After a change of practice, equilibration of soil carbon levels generally takes decades, and may take a century or more (Johnson et al., 1995). Conversely, additionality can be a transient quality. Therefore, regardless of the method used to assess it, assessments will have to be repeated or updated through time, meaning ongoing transaction costs.

\subsection{Updates to additionality}

Additionality is often mistakenly thought of as being a comparison of 'before and after' the introduction of the policy when it is actually a question of 'with and without' the policy. The 'before' situation is observable and fixed, whereas the 'without' scenario is unobservable and dynamic. To illustrate, suppose that a CFI-like policy with a common-practice approach to determining additionality had existed at the time that no-till was being adopted in Australia. Initially, early adopters could have claimed benefits for additional soil carbon because no-till was not commonly practised. It could well have been genuinely additional at this stage, as the knowledge and technology required to implement it profitably was still being developed. As no-till became more profitable, the sequestration it provides would have become less costly; 
at a certain point, it would become profitable enough not to require income from sequestration for widespread adoption and it would no longer be additional.

In time, adoption of no-till would have increased to around $90 \%$ of farmers (this is what happened without the policy) (D’Emden \& Llewellyn, 2006). Clearly almost all of this adoption would be non-additional. Furthermore, although sequestration by early adopters was additional at the time, it was only temporarily additional because ultimately that sequestration would have occurred anyway without the policy. The GHG concentration in the atmosphere would eventually be the same with or without promotion of this practice by the sequestration policy.

If such a change in a sequestration practice’s additionality is anticipated, it may make sense not to treat the practice as additional, even on a temporary basis. This would avoid spending money on actions that ultimately make little or no difference to climate change, and could otherwise have been spent on more effective mitigation. Sequestration practices that are 'cost-effective' because they are close to being viable in their own right (i.e., a low carbon price is sufficient to make the practice attractive to landholders) may often be those practices whose additionality is likely to change with time.

If a future change in additionality is not anticipated, but it becomes apparent that a practice once additional is no longer so, government appears to have two options: write-off the funds that have been lost (plus the climatic gains that could have otherwise been made from alternative investments), or require participants to bear the cost of the retrospective change in additionality (e.g. by purchasing replacement abatement). The latter option is unlikely to be politically feasible. 
A second challenge related to the dynamics of additionality is that the benchmark agricultural practice may change even if the sequestering practice remains additional. Agriculture in the $20^{\text {th }}$ century was characterised by rapid and dramatic improvements in production technologies, and large changes in prices, such that there would have been frequent changes in the benchmark practice in many cases.

To illustrate the potential consequences of this, suppose that a farmer replaces a benchmark practice that was neither storing nor emitting carbon with a sequestering activity that would accumulate an additional 13.2 tonnes of carbon over the next 35 years (areas $X+Y$ in Figure 2(b)).

(a)

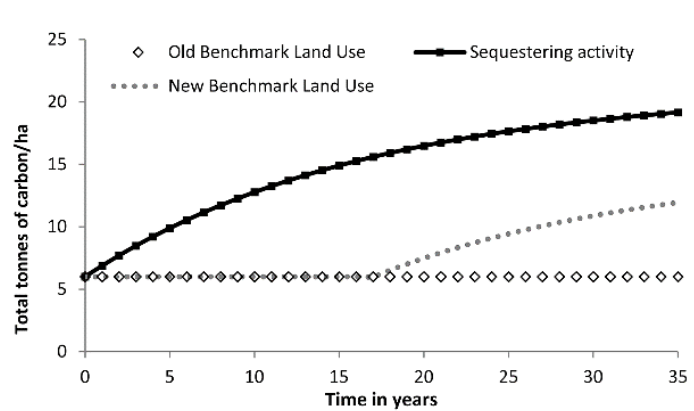

(b)

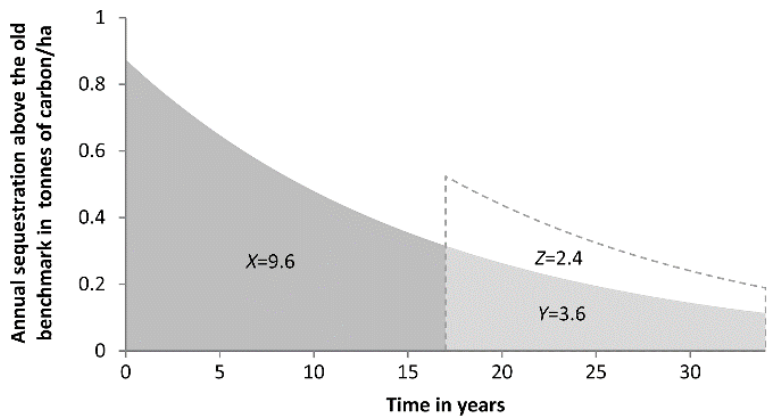

Figure 2. (a) Amount of carbon sequestered as a function of time. (b) The annual amount of sequestration above the old benchmark.

Imagine that after 17 years the landholder would have switched from the old benchmark practice to a new benchmark, had they not otherwise been engaged in the sequestration program. Suppose that this new benchmark also happens to sequester carbon-although this is not the reason it has become preferable to the old benchmark-and from years 18 to 35 it would have sequestered 6 tonnes of carbon (areas $Y+Z$ ). Notably, this is more than the 
claimed sequestering practice stores over years 18 to 35 (area Y), largely because sequestration occurs most rapidly shortly after a change in practice and then decreases over time. Therefore in principle, once the benchmark was updated, the farmer should have to relinquish offsets (or repay government payments) equivalent to area $Z$. However, like the previous example where a practice changed from additional to non-additional after a period of time, we anticipate that any requirement to repay payments for sequestration (undertaken in good faith but no longer additional) would be politically unacceptable. After all, the farmer would still be maintaining the sequestering practice, and the absolute amount of carbon in their soils would still be increasing by the amount shown in area $Y$.

These examples illustrate that in a theoretically-sound policy where participation is voluntary, landholders are not paid for the absolute amount of sequestration, but the additional amount sequestered relative to the benchmark. Consequently, a farmer's obligation should be to permanently maintain the claimed amount of sequestration over and above what would otherwise have happened (which may change with time), rather than the absolute amount of carbon that has been sequestered. This remains true even after claiming has ceased, and the stored carbon is being maintained for permanence reasons.

The need to revise additionality rulings over time because of the ephemeral nature of additionality is recognised in the literature (e.g., Gustavsson et al., 2000). However, it has not previously been acknowledged, either in the literature or by policymakers, that failing to apply these updates retrospectively to sequestration claimed in the past will reduce the benefits of sequestration, and result in an opportunity cost of having otherwise spent those funds on effective mitigation. In the original CFI, not only were updates to additionality not applied retrospectively, but sequestration could be claimed for another seven years after 
practices have been deemed to be no longer additional (DCCEE, 2012). This is clearly inconsistent with the principle of additionality.

Additionality is required with policies that provide financial rewards for mitigation (either by the sale of offsets or by government payments) and where participation is voluntary. It is not an issue for policy approaches that impose penalties on firms or individuals for not mitigating, by requiring them to pay a tax or purchase an emissions permit. Therefore, additionality is not an inherent requirement of sequestration per se. It is just that sequestering activities are implemented almost exclusively under the voluntary, financial reward type of policy framework, meaning that additionality is associated with sequestration almost as a matter of course. Furthermore with sequestration, ensuring additionality is made more challenging by the theoretical need to apply updates to additionality retrospectively. In contrast, the benefits of emissions reductions cannot be eroded in the same way, meaning retrospective updating is not an issue for them. 


\section{Permanence}

To ensure permanence, sequestration schemes typically have rules that require sequestration to be maintained and not re-released for a certain duration or until replacement abatement is purchased (at the contemporary carbon price). The CFI's original permanence rules represented a combination of both: farmers were required to maintain sequestration for 100 years ${ }^{4}$, but could opt out of the scheme before then by purchasing and surrendering permits (the 2014 revised CFI policy, based on government payments, introduced the option of a 25year period for maintaining sequestration, with a discount on the payments).

The use of 100 years as the criterion for 'permanence' constitutes a gamble that climate change will have been solved by that time, so that the re-release of sequestered carbon will not be a problem. The gamble is increased because the physical dynamics of $\mathrm{CO}_{2}$ in the atmosphere mean that the 100-year rule would result in higher future atmospheric concentrations of $\mathrm{CO}_{2}$ than if there had never been sequestration. To illustrate, suppose that in $2015 \mathrm{D}$ units of $\mathrm{CO}_{2}$ emissions are mitigated either by offsetting them with sequestration, or by preventing/reducing emissions. The properties of the carbon cycle mean that a reduction in $\mathrm{CO}_{2}$ has a diminishing effect on atmospheric $\mathrm{CO}_{2}$ over time due to reequilibration of carbon from the atmosphere with other sinks, particularly the ocean (Archer, 2005). As a consequence, releasing the sequestered carbon in 2115 , adding $D$ units of $\mathrm{CO}_{2}$ to the atmosphere, raises the 'offset with sequestration' curve above the 'not mitigated' curve in Figure 3 (Kirschbaum, 2006 made a similiar observation). So although sequestration buys time for the ' 100 -year gamble' to play out, if it turns out to be a losing wager, the approach could actually make the problem worse.

\footnotetext{
${ }^{4} 100$ years after credits are first claimed. Subsequent claims made for the same project do not 'reset' the 100year count, meaning that carbon sequestered later needs to be stored for progressively less time.
} 


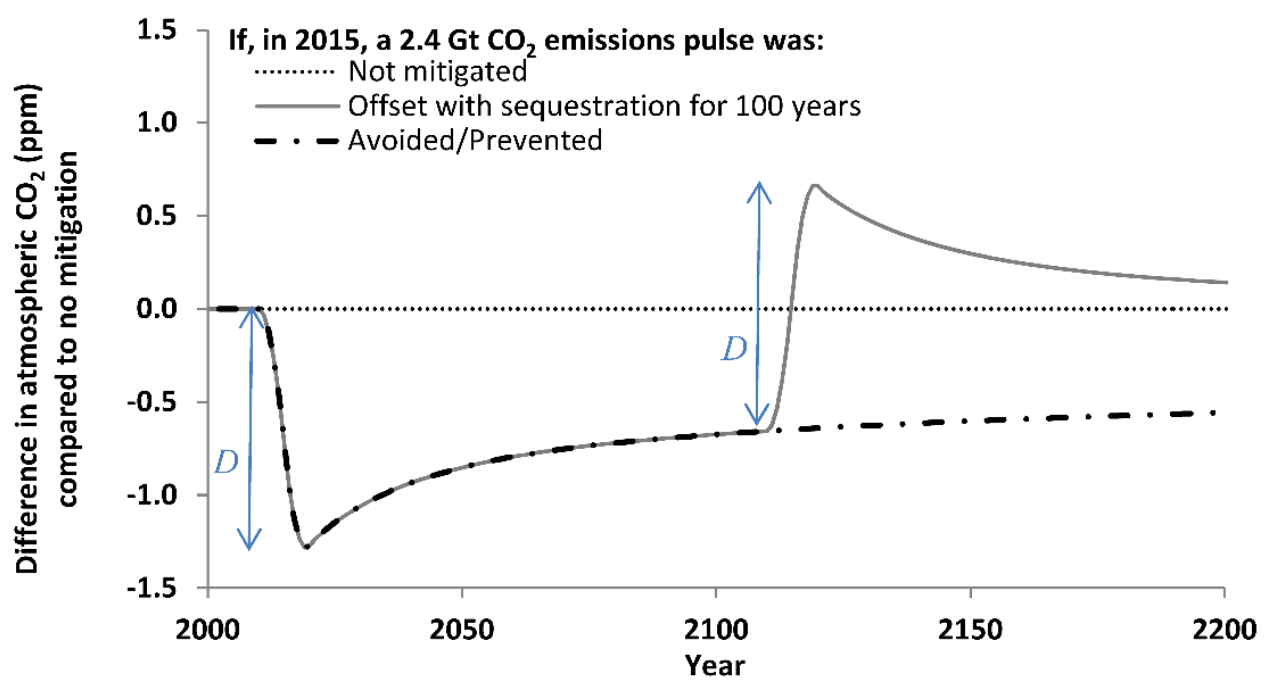

Figure 3. Implications of either i) offsetting with sequestration for 100 years or ii) preventing an emissions pulse, compared to not mitigating it at all (as predicted by the Model for the Assessment of Greenhouse Gas Induced Climate Change version 5.3 (Wigley et al., 2009), with the once-off emission pulse occurring against a background of the WRE450 emissions scenario).

The gamble can be avoided simply by not permitting the free release of sequestered carbon after what is essentially an arbitrary period such as 100 years. Instead, the concept of permanence would be applied literally. It is desirable to maintain the option of allowing participants to leave the scheme by purchasing replacement abatement as this would not sacrifice the GHG integrity of the program but would potentially increase participation.

Indeed encouragement of participation is one possible argument for the original CFI's 'free' release at 100 years. It might be seen as making permanence less onerous. However, for two reasons, the additional incentive for participation is likely to be minor. Firstly, the costs that would be saved by utilising this 'free' release are greatly reduced by discounting over 100 years (e.g., by more than $99 \%$, at a discount rate of $5 \%$ ). Secondly, there is a probability that 
the climate change problem will have been resolved by that time (e.g., through development of renewable energy technologies) so that the cost of emissions permits will have fallen greatly, potentially to zero. This outcome is, after all, what policy makers are relying on when they specify the arbitrary time frame of 100 years for 'permanence'. In that eventuality, the cost to participants from purchasing permits in order to leave the scheme would be lower still. In the alternative scenario, where climate change is unresolved, it seems preferable not to leave our descendants with a problem of large emissions of formerly sequestered carbon.

In contrast to sequestration, a reduction in emissions also buys time but without the risk of making the situation worse in the future (Figure 3). There are no questions over how long they should be maintained, nor any risk of re-releases exacerbating climate change in the future. It is therefore potentially inefficient for policies like the CFI to value emission reductions and less enduring sequestration equally (Feng et al., 2002; Gramig, 2012; van Kooten, 2009). Although there may be benefits from temporally removing emissions from the atmosphere with sequestration, if this sequestration and permanent emissions reductions are both to be legitimately valued at the same carbon price then permanence requirements should have no time limit, and instead simply require landholders to relinquish replacement permits if they release previously sequestered carbon. Permanence provisions can interact with leakage to create further challenges, as outlined in the next section.

The Alberta scheme does not require landholders to maintain sequestration to ensure permanence. Instead, the amount of credits granted for an activity is scaled down by the probability that the sequestration might be undone in the next 20 years $(7.5-12.5 \%$ probability, set by surveying experts) (Government of Alberta, 2012). We note that, if 7.5$12.5 \%$ is indeed an accurate reflection of the probability of losing the sequestered carbon in 
the absence of any mechanism to enforce its retention, then, by definition, it would appear that most of the sequestered carbon is not additional. That said, Roberts and Lubowski (2007) observed that a policy may partially influence land management beyond the life of the policy. A relevant example would be where reverting to the original practice is prohibitively costly (e.g., the cost of bringing land planted to trees back into arable cultivation). However, we suspect such that situations are less likely for agricultural practices sequestering carbon in soils than with conversion to forestry.

\section{Leakage}

Leakage can be categorised into two different forms:

1. 'Indirect' — emissions resulting from substitutions or market adjustments occurring in response to the sequestration, potentially in other countries.

2. 'Direct' - emissions directly resulting from the sequestration activities.

Indirect leakage can be significant, and has received considerable attention in the literature (e.g., Alix-Garcia, Shapiro, \& Sims, 2012; Gan \& McCarl, 2007; Lee, McCarl, Schneider, \& Chen, 2007; Montserrat \& Sohngen, 2009; Sun \& Sohngen, 2009). Despite this scholarly attention, accounting for indirect leakage is very difficult when it comes to policy implementation, and so it tends to be ignored (as it is in the CFI). While not condoning this, we focus on direct leakage, which has received less attention in the literature. Perhaps this is because, at face value, it appears more straight-forward to address. However, there are challenges involved with developing policy to deal with emissions that occur as a direct result of adoption of a sequestering activity. 
Many of the emissions directly associated with sequestration in soil result from agricultural activities. Agricultural emissions are dynamic, spatially heterogeneous, and difficult to measure. Methods for estimating them tend to be generic and may not reflect actual leakage at particular locations (Cowie et al., 2012; Thamo, Kingwell, \& Pannell, 2013). Assessing them more precisely is possible, but involves higher transaction costs.

A second challenge with leakage is that there may be practices that appear desirable to landholders in the short term despite being undesirable in the long term. Consider the replacement of cropping land use with perennial pasture (e.g., Thomas, Sanderman, Eady, Masters, \& Sanford, 2012). This land-use change was recently approved for crediting under the CFI (Department of the Environment, 2014). Although stylised, the dashed line in Figure 4 is consistent with the pattern of increasing soil carbon following the conversion of cultivated crop land to permanent pasture (Sanderman, Farquharson, \& Baldock, 2010). However, pasture is most commonly used to feed livestock, which emit methane, an important GHG. Suppose that the livestock grazing this pasture 'leak' 0.6 t/ha/year of carbon dioxide equivalents $\left(\mathrm{CO}_{2} \mathrm{e}\right)$ (dotted line $)^{5}$.

Although the sequestration rate is initially much higher than the leakage, as it plateaus over 100 years it is eventually overtaken by the smaller, but constant, leakage (at around year 90 in Figure 4). The net level of sequestration would peak at about 30 years. Unfortunately, it is not feasible to maintain the year-30 situation in subsequent years. If the pasture is retained (and grazed), leakage occurs more rapidly than ongoing sequestration. If the pasture is retained

\footnotetext{
${ }^{5}$ Because they occur at the same location as the sequestration, many would classify these methane emissions not as 'leakage' but rather as part of the emissions balance of a sequestration project. However, for our purposes whether they technically constitute leakage or not is immaterial. The key point is that these methane emissions are caused by the adoption of the sequestering practice and counteract it.
} 
and not grazed, the opportunity cost of cropping income is likely to exceed the benefits of sequestration. If the pasture is converted back to cropping, to avoid further leakage, the sequestered carbon is re-emitted over time. In this situation, from a climate-change perspective, it appears preferable not to commence the sequestration activity in the first place. However, the exclusion of such practices from a scheme because they could be undesirable in the long term may not always occur for two reasons. Firstly, if the practice appears desirable in the short term it may be politically convenient to ignore longer-term undesirability. Secondly, even if the political will is present, determining long-term desirability of a practice ex ante may not be easy, as rates (and timing) of leakage may change in the future, and anticipated and actual measurements of sequestration may diverge.

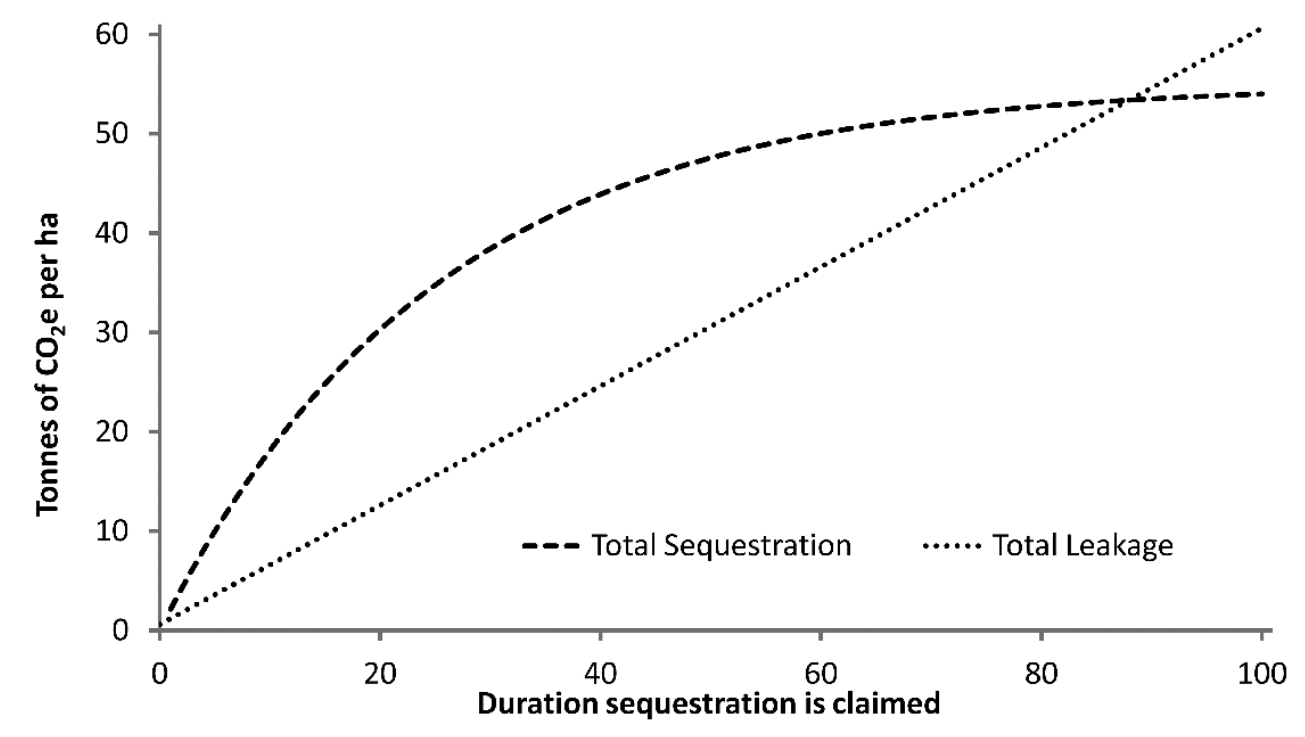

Figure 4. Cumulative sequestration and leakage as a function of the time credits are claimed.

The CFI legislation does not clearly define how sequestering practices that potentially generate more emissions than they sequester should be dealt with, although the legislation does allow some discretionary powers in these matters. Perhaps the simplest way for a policy to deal with this situation is to require leakage to be paid for when it occurs, at the 
contemporary carbon price. However, even if leakage is accounted for in this way, a sequestration practice that involves significant leakage could still appear financially attractive. This creates the possibility that landholders could be paid to undertake practices that, in the long run, leak more than they sequester, and that this leakage could be locked in by permanence conditions.

To illustrate, using the example from Figure 4, suppose that the price of offsets (or the government payment) is $\$ 23 / \mathrm{t}$ of $\mathrm{CO}_{2} \mathrm{e}$ (Australia’s price in 2012), increasing at 2.5\% per annum in real terms for the entire period, and that the real discount rate is $5 \%$. Then claiming credits for more than 16 years would generate enough income to cover the expense of relinquishing credits for leakage over 100 years. From the farmer's perspective, under the conditions operating in the original CFI, the most profitable course of the action would be to continue with the sequestering practice (and associated leakage) until a 'free release' from permanence obligations could be obtained after 100 years. But implementing the project for this profit-maximising 100-year period would 'leak' 6.5 tonnes more $\mathrm{CO}_{2} \mathrm{e}$ than it would sequester (Figure 4). In other words, despite eventually requiring more credits than it generates, the practice would be financially attractive for the farmer to pursue. This is because income from sequestration occurs mainly in earlier years, when sequestration rates are highest, whereas a larger share of leakage costs occurs later on and are therefore discounted heavily. This result is possible whenever the carbon price increases at a rate lower than the discount rate.

Importantly, potential participants in the program would need to expect that the carbon price will increase at a rate lower than the discount rate in order to be willing to participate. If they expect the carbon price to increase at a faster rate than the discount rate, then it would always 
appear optimal to defer commencement of sequestration until the future, when prices have increased by more than enough to outweigh the effect of discounting (this is because sequestration can occur only once: now or later). The landowner's optimal course of action would be to delay sequestration until the carbon price is increasing at a rate less than the discount rate (McCarl \& Sands, 2007; van ’t Veld \& Plantinga, 2005).

Although these financial results provide only a stylised example, they do serve to highlight the potential risk for programs that accept sequestration activities with significant levels of leakage, particularly where the mitigation and resultant leakage occur over different timeframes. They may find that there are willing suppliers of offsets from these activities (or willing participants in a payment-based scheme), even where participants will be charged the going price for that leakage. Policymakers would be well advised not to include in programs any sequestration practices where leakage is likely to outweigh sequestration within a certain time frame.

Leakage can, of course, also be an issue for emission reductions. However, because emission reductions are not subject to permanence requirements, in their case there is less disparity between the timing of abatement and the associated leakage, meaning that the assessment of direct leakage is far simpler.

\section{Other drawbacks of sequestration}

Some argue that sequestration could provide an interim 'bridge' to the future, buying time for the development of improved technologies that allow lower-cost reductions in atmospheric $\mathrm{CO}_{2}$ (e.g., Lal, 2002). However, there are reasons to doubt whether the benefits of this 
proposed 'bridging' are sufficient to outweigh the disadvantages of sequestration as an abatement strategy.

Firstly, a sequestration 'bridge' may be counterproductive by reducing incentives to innovate. The use of sequestration in the short term reduces the market price for emission permits (or in the absence of an emissions trading scheme, makes it easier to meet abatement targets), potentially reducing the incentive for early development of the required technologies (van Kooten, 2009; van Kooten \& de Vries, 2013).

Secondly, carbon prices will need to increase for some years, perhaps decades, so that they reach a level that provides the required incentives for abatement and innovation (Keeler, 2005; van 't Veld \& Plantinga, 2005). However, as noted earlier, if the carbon price is rising faster than the discount rate there is a financial incentive to defer the commencement of sequestration (because it can store a finite amount of carbon) (McCarl \& Sands, 2007; van 't Veld \& Plantinga, 2005). There is an irony here, in that a rapidly increasing carbon price, which might be thought to signal a need for urgent action, would actually discourage early sequestration. The same is not true of emissions reductions.

Thirdly, as we have demonstrated, leakage and/or the re-release of sequestered carbon may increase the amount of abatement that any future technologies will need to provide. This is particularly the case for programs that allow re-emission after an arbitrary fixed period of sequestration. Similarly, future changes in climate may reduce the equilibrium amount of carbon a given practice will maintain sequestered (Hoyle et al., 2013). If this new equilibrium is less than the amount previously stored, then what was a carbon sink may become a carbon source due to the changed climate (Goetz, Hritonenko, Mur, Xabadia, \& Yatsenko, 2013). 
Given that GHG concentrations are more likely to be approaching 'dangerous thresholds' in the future than they are currently, any short-terms gains made by sequestration now may be a false economy.

Fourthly, in addition to abatement, social and environmental co-benefits are often cited as an additional impetus for developing sequestration policies. However, the externalities from reducing or preventing emissions may be equally positive (Elbakidze \& McCarl, 2007). Furthermore, policies focused on maximising other externalities may not achieve mitigation very efficiently and, vice versa, policies that maximise sequestration may deliver little in the way of other benefits (Caparrós \& Jacquemont, 2003). Therefore, whilst the potential of a sequestration policy to provide additional co-benefits may be important, the extent to which these benefits are likely to be delivered should be analysed carefully rather than assumed (Bradshaw et al., 2013), particularly as there is potential for purported co-benefits to be overstated by rent seekers.

Fifthly, beyond the economic challenges discussed here, quantifying the amount of sequestration is very challenging and also involves (potentially large) transaction costs (García-Oliva \& Masera, 2004; Subak, 2000). In comparison, transaction costs for quantifying emission reductions are likely to be lower in many cases.

Lastly, we have focused on the challenges of designing policies that aim to achieve the sequestration that is considered to be theoretically possible. However, the mitigation theoretically achievable with sequestration has itself been queried in recent studies (e.g., Lam, Chen, Mosier, \& Roush, 2013; Powlson, Whitmore, \& Goulding, 2011; Robertson \& Nash, 2013). Furthermore, how immediately the mitigation potential of sequestration could 
actually be realised has also been questioned (Sommer \& Bossio, 2014), throwing doubt on the capacity for sequestration to provide a short-term 'bridge' to future reductions in emissions.

\section{Conclusion}

There are many challenges to designing sequestration polices to ensure that they achieve genuine mitigation in a way that is cost-effective. Although additionality, leakage and permanence are issues for all voluntary abatement policies, unique characteristics of sequestration mean that these issues are particularly difficult for sequestration. These characteristics include: that the amount of abatement achievable with soil sequestration from a piece of land is finite (unless the $\mathrm{CO}_{2}$ is first re-emitted), after which there is no option but to reduce emissions; that sequestration occurs rapidly at first but then plateaus at a maximum level; that sequestered soil carbon can be re-emitted if the new management regime is not maintained; and that some sequestration activities result in leakage of other emissions, potentially over different timeframes.

To contain transaction costs in the CFI, additionality is assessed based on the proportion of the relevant population undertaking the practice. However, this 'common-practice' approach rules out what are likely to be the least costly, genuinely additional abatement measures: increases in adoption where there is already (without the carbon price) moderate adoption. These increases could be in the number of adopters or, for farmers who have already adopted to a certain amount, in the extent the adoption is practised. The common-practice approach to assessing additionality also unavoidably results in non-additional practices qualifying for benefits, and genuinely additional practices being excluded from them. The choice of the 
threshold level of adoption determines the balance between these two problems, but cannot overcome them.

Most importantly, the intended advantage of this approach (reduced transaction costs) is at best temporary. Once the scheme is in place, assessment of additionality requires estimation of what the land use would have been in the absence of the scheme. The common-practice approach provides no assistance with this counterfactual question. Indeed it would seem to require the sort of analysis of optimal farming practices that was meant to be avoided by use of the common-practice approach.

Finally, the counterfactual scenario changes over time, so the additionality of sequestration cannot be presumed to be permanent. Theoretically this means that additionality should not only be periodically re-evaluated, but any updates should also be applied retrospectively, although this is likely to be politically infeasible.

In relation to the requirement for sequestration to be permanent, our analysis provides a warning against defining permanence as a period of arbitrary length, such as 100 years, after which re-emission of sequestered carbon is permitted. Because of the dynamics of the carbon cycle, this may result in future atmospheric carbon levels being greater than they would have been in the absence of sequestration.

We show that, under plausible circumstances, a sequestering activity can ultimately 'leak' more GHGs than it removes from the atmosphere. It can be financially attractive to a landholder for this to occur, even if leakage is quantified and charged for at the contemporary price. Added to this is the risk that, once the initial period of rapid sequestration is over, 
requirements for permanence may lock in leakage at annual rates that exceed annual sequestration rates.

In the face of these challenges and potential perverse outcomes, policymakers essentially have three options. Firstly, they can implement stringent systems to ensure the veracity of sequestration. The high transaction costs associated with this option will make sequestration less competitive, and sequestration's overall contribution to international action on climate change may be minor. Secondly, they can simplify the process, reducing its stringency, as appears to have been done in Alberta's offset scheme and Australia's revised CFI. This would no doubt be popular with farmer groups and polluters, both of whom would stand to benefit. Although it will boost participation, it will also be inefficient and the amount of genuinely additional mitigation from carbon sequestration in the long run may only be small. The third alternative is to exclude sequestration options that suffer from the challenges identified here. In considering these options, sequestration should be seen as a means to an environmental end and not an end in itself (Trexler, 2011). It should also be remembered that, once implemented, poor policy can be difficult to remove as it creates a group of beneficiaries with an incentive to lobby for its continuation.

Overall, our judgement is that the third option of excluding soil carbon sequestration activities from carbon abatement policy should be carefully considered. Although there undoubtedly are benefits to increasing the carbon content of soils, given the challenges, risks and potential for perverse outcomes and high transaction costs, soil carbon sequestration may not be an efficient approach to mitigating climate change, especially if the sequestration is used as a direct substitute for preventing or reducing emissions. Where sequestration practices are associated with significant leakage, or where they are anticipated to have the 
potential to become very widely adopted even without policy support, their inclusion in abatement policy seems particularly ill-advised.

\section{Funding}

This work was supported by the University of Western Australia, the ARC Centre of

Excellence for Environmental Decisions, and the Grains Research and Development

Corporation.

\section{References}

Alix-Garcia, J. M., Shapiro, E. N., \& Sims, K. R. E. (2012). Forest Conservation and Slippage: Evidence from Mexico's National Payments for Ecosystem Services Program. [Article]. Land Economics, 88(4), 613-638.

Antle, J., Capalbo, S., Mooney, S., Elliott, E., \& Paustian, K. (2003). Spatial heterogeneity, contract design, and the efficiency of carbon sequestration policies for agriculture. Journal of Environmental Economics and Management, 46(2), 231-250. doi: 10.1016/s0095-0696(02)00038-4

Archer, D. (2005). Fate of fossil fuel $\mathrm{CO}_{2}$ in geologic time. Journal of Geophysical Research, 110(C9), C09S05. doi: 10.1029/2004jc002625

Bradshaw, C. J. A., Bowman, D. M. J. S., Bond, N. R., Murphy, B. P., Moore, A. D., Fordham, D. A., et al. (2013). Brave new green world - Consequences of a carbon economy for the conservation of Australian biodiversity. Biological Conservation, 161(0), 71-90. doi: http://dx.doi.org/10.1016/j.biocon.2013.02.012

Cacho, O. J., Lipper, L., \& Moss, J. (2013). Transaction costs of carbon offset projects: A comparative study. Ecological Economics, 88(0), 232-243. doi: http://dx.doi.org/10.1016/j.ecolecon.2012.12.008

Caparrós, A., \& Jacquemont, F. (2003). Conflicts between biodiversity and carbon sequestration programs: economic and legal implications. Ecological Economics, 46(1), 143-157. doi: http://dx.doi.org/10.1016/S0921-8009(03)00138-1

Capon, T., Harris, M., \& Reeson, A. (2013). The Design of Markets for Soil Carbon Sequestration. Economic Papers: A journal of applied economics and policy, 32(2), 161-173. doi: 10.1111/1759-3441.12034

Claassen, R., Horowitz, J., Duquette, E., \& Ueda, K. (2014). Additionality in U.S. Agricultural Conservation and Regulatory Offset Programs: USDA Economic Research Report Number 170.

Climate Change Authority. (2014a). Carbon Farming Initiative Review Report. Canberra: Australian Government.

Climate Change Authority. (2014b). Coverage, Additionality and Baselines - Lessons from the Carbon Farming Initiative and other schemes. Melbourne: Commonwealth of Australia (Climate Change Authority). 
Cowie, A., Eckard, R., \& Eady, S. (2012). Greenhouse gas accounting for inventory, emissions trading and life cycle assessment in the land-based sector: a review. Crop and Pasture Science, 63(3), 284-296. doi: http://dx.doi.org/10.1071/CP11188

D’Emden, F. H., \& Llewellyn, R. S. (2006). No-tillage adoption decisions in southern Australian cropping and the role of weed management. Australian Journal of Experimental Agriculture, 46(4), 563-569. doi: http://dx.doi.org/10.1071/EA05025

DCCEE. (2010). Design of the Carbon Farming Initiative-Consultation Paper. Canberra, ACT: Department of Climate Change and Energy Efficiency.

DCCEE. (2012). Outcomes of consultation Retrieved 19 Sept, 2012, from http://www.climatechange.gov.au/government/initiatives/carbon-farminginitiative/recent-developments/outcomes-of-consultation.aspx

Department of the Environment. (2014). Sequestering carbon in soils in grazing systems Retrieved July 9, 2014, from http://www.climatechange.gov.au/reducingcarbon/carbon-farming-initiative/methodologies/methodology-proposals/sequesteringcarbon-soils-grazing-systems

Eby, M., Zickfeld, K., Montenegro, A., Archer, D., Meissner, K. J., \& Weaver, A. J. (2009). Lifetime of Anthropogenic Climate Change: Millennial Time Scales of Potential CO2 and Surface Temperature Perturbations. Journal of Climate, 22(10), 2501-2511. doi: 10.1175/2008jcli2554.1

Elbakidze, L., \& McCarl, B. A. (2007). Sequestration offsets versus direct emission reductions: Consideration of environmental co-effects. Ecological Economics, 60(3), 564-571. doi: http://dx.doi.org/10.1016/j.ecolecon.2005.12.014

Feng, H., Zhao, J., \& Kling, C. L. (2002). The Time Path and Implementation of Carbon Sequestration. American Journal of Agricultural Economics, 84(1), 134-149.

Fosci, M. (2013). Balance sheet in the REDD +: Are global estimates measuring the wrong costs? Ecological Economics, 89(0), 196-200. doi: http://dx.doi.org/10.1016/j.ecolecon.2012.11.022

Gan, J., \& McCarl, B. A. (2007). Measuring transnational leakage of forest conservation. Ecological Economics, 64(2), 423-432. doi: http://dx.doi.org/10.1016/j.ecolecon.2007.02.032

García-Oliva, F., \& Masera, O. R. (2004). Assessment and Measurement Issues Related to Soil Carbon Sequestration in Land-Use, Land-Use Change, and Forestry (LULUCF) Projects under the Kyoto Protocol. Climatic Change, 65(3), 347-364. doi: 10.1023/B:CLIM.0000038211.84327.d9

Goetz, R. U., Hritonenko, N., Mur, R., Xabadia, À., \& Yatsenko, Y. (2013). Forest management for timber and carbon sequestration in the presence of climate change: The case of Pinus Sylvestris. Ecological Economics, 88(0), 86-96. doi: http://dx.doi.org/10.1016/j.ecolecon.2013.01.012

Government of Alberta. (2012). Technical Seed Document for the Quantification Protocol for Conservation Cropping. Edmonton: Alberta Environment and Water.

Gramig, B. M. (2012). Some Unaddressed Issues in Proposed Cap-and-Trade Legislation Involving Agricultural Soil Carbon Sequestration. American Journal of Agricultural Economics, 94(2), 360-367. doi: 10.1093/ajae/aar097

Gustavsson, L., Karjalainen, T., Marland, G., Savolainen, I., Schlamadinger, B., \& Apps, M. (2000). Project-based greenhouse-gas accounting: guiding principles with a focus on baselines and additionality. Energy Policy, 28(13), 935-946. doi: 10.1016/s03014215(00)00079-3

Hoyle, F. C., D’Antuono, M., Overheu, T., \& Murphy, D. V. (2013). Capacity for increasing soil organic carbon stocks in dryland agricultural systems. Soil Research, 51(8), 657667. doi: http://dx.doi.org/10.1071/SR12373 
Johnson, M. G., Levine, E. R., \& Kern, J. S. (1995). Soil organic matter: Distribution, genesis, and management to reduce greenhouse gas emissions. Water, Air, \& Soil Pollution, 82(3), 593-615. doi: 10.1007/bf00479414

Jones, C. A., Nickerson, C. J., \& Heisey, P. W. (2013). New Uses of Old Tools? Greenhouse Gas Mitigation with Agriculture Sector Policies. Applied Economic Perspectives and Policy, 35(3), 398-434. doi: 10.1093/aepp/ppt020

Keeler, A. G. (2005). Sequestration rental policies and price path of carbon. Climate Policy, 4(4), 419-425.

Kirschbaum, M. U. F. (2006). Temporary Carbon Sequestration Cannot Prevent Climate Change. Mitigation and Adaptation Strategies for Global Change, 11(5), 1151-1164. doi: 10.1007/s11027-006-9027-8

Kragt, M. E., Pannell, D. J., Robertson, M. J., \& Thamo, T. (2012). Assessing costs of soil carbon sequestration by crop-livestock farmers in Western Australia. Agricultural Systems, 112, 27-37.

Lal, R. (2002). Soil carbon dynamics in cropland and rangeland. Environmental Pollution, 116(3), 353-362. doi: 10.1016/s0269-7491(01)00211-1

Lam, S. K., Chen, D., Mosier, A. R., \& Roush, R. (2013). The potential for carbon sequestration in Australian agricultural soils is technically and economically limited. [Article]. Nature Scientific Reports, 3, 2179. doi: 10.1038/srep02179

http://www.nature.com/srep/2013/130710/srep02179/abs/srep02179.html\#supplementaryinformation

Lee, H.-C., McCarl, B., Schneider, U., \& Chen, C.-C. (2007). Leakage and Comparative Advantage Implications of Agricultural Participation in Greenhouse Gas Emission Mitigation. Mitigation and Adaptation Strategies for Global Change, 12(4), 471-494. doi: 10.1007/s11027-006-2941-y

Lewandrowski, J., \& Zook, K. (2015). GHG Mitigation in the Absence of a National Carbon Market. Choices. Issue: Climate Change and Agriculture: Revisiting the Evidence and Potential Solutions, 30 (2).

McCarl, B. A. (2006). Permanence, Leakage, Uncertainty and Additionality in GHG Projects. In G. A. Smith (Ed.), Terrestrial GHG Quantification and Accounting: A publication by Environmental Defense.

McCarl, B. A., \& Sands, R. (2007). Competitiveness of terrestrial greenhouse gas offsets: are they a bridge to the future? Climatic Change, 80(1), 109-126. doi: 10.1007/s10584006-9168-5

Meyers, S. (1999). Additionality of Emissions Reductions From Clean Development Mechanism Projects: Issues and Options for Project-Level Assessment. Berkeley, CA.: Lawrence Berkeley National Laboratory.

Montserrat, A., \& Sohngen, B. (2009). How big is leakage from forestry carbon credits? Estimates from a global model. IOP Conference Series: Earth \& Enviro Science, 6(5), 052011.

Murray, B. (2015). Why Have Carbon Markets Not Delivered Agricultural Emission Reductions in the United States? Choices. Issue: Climate Change and Agriculture: Revisiting the Evidence and Potential Solutions, 30 (2).

Murray, B., Sohngen, B., \& Ross, M. (2007). Economic consequences of consideration of permanence, leakage and additionality for soil carbon sequestration projects. Climatic Change, 80(1), 127-143. doi: 10.1007/s10584-006-9169-4

Neales, S. (2014, June 13). Farmers to win from carbon fund, The Australian. Retrieved from http://www.theaustralian.com.au/national-affairs/policy/farmers-to-win-fromcarbon-fund/story-e6frg6xf-1226952562021 
Pannell, D. J., Marshall, G. R., Barr, N., Curtis, A., Vanclay, F., \& Wilkinson, R. (2006). Understanding and promoting adoption of conservation practices by rural landholders. Australian Journal of Experimental Agriculture, 46(11), 1407-1424. doi: doi:10.1071/EA05037

Powlson, D. S., Whitmore, A. P., \& Goulding, K. W. T. (2011). Soil carbon sequestration to mitigate climate change: a critical re-examination to identify the true and the false. European Journal of Soil Science, 62(1), 42-55. doi: 10.1111/j.13652389.2010.01342.x

Roberts, M. J., \& Lubowski, R. N. (2007). Enduring Impacts of Land Retirement Policies: Evidence from the Conservation Reserve Program. Land Economics, 83(4), 516-538.

Robertson, F., \& Nash, D. (2013). Limited potential for soil carbon accumulation using current cropping practices in Victoria, Australia. Agriculture, Ecosystems \& Environment, 165(0), 130-140. doi: http://dx.doi.org/10.1016/j.agee.2012.11.004

Robertson, M. J., Pannell, D. J., \& Chalak, M. (2012). Whole-farm models: a review of recent approaches. Australian Farm Business Management Journal, 9(3), 13-26.

Sanderman, J., Farquharson, R., \& Baldock, J. (2010). Soil Carbon Sequestration Potential: A review for Australian agriculture. Canberra: CSIRO Land and Water.

Sommer, R., \& Bossio, D. (2014). Dynamics and climate change mitigation potential of soil organic carbon sequestration. Journal of Environmental Management, 144(0), 83-87. doi: http://dx.doi.org/10.1016/j.jenvman.2014.05.017

Subak, S. (2000). Agricultural soil carbon accumulation in North America: considerations for climate policy. Global Environmental Change, 10(3), 185-195. doi: 10.1016/s09593780(00)00026-1

Sun, B., \& Sohngen, B. (2009). Set-asides for carbon sequestration: implications for permanence and leakage. Climatic Change, 96(3), 409-419. doi: 10.1007/s10584-0099628-9

Swallow, B. M., \& Goddard, T. W. (2013). Value chains for bio-carbon sequestration services: Lessons from contrasting cases in Canada, Kenya and Mozambique. Land Use Policy, 31(0), 81-89. doi: http://dx.doi.org/10.1016/j.landusepol.2012.02.002

Thamo, T., Kingwell, R. S., \& Pannell, D. J. (2013). Measurement of greenhouse gas emissions from agriculture: economic implications for policy and agricultural producers. Australian Journal of Agricultural and Resource Economics, 57, 234-252.

Thomas, D. T., Sanderman, J., Eady, S. J., Masters, D. G., \& Sanford, P. (2012). Whole Farm Net Greenhouse Gas Abatement from Establishing Kikuyu-Based Perennial Pastures in South-Western Australia. Animals, 2(3), 316-330.

Trexler, M. C. (2011). GHG measurement and management are vital, but always be looking to advance the end game of mitigating climate change. Greenhouse Gas Measurement and Management, 1(2), 77-79. doi: 10.1080/20430779.2011.579353

van 't Veld, K., \& Plantinga, A. (2005). Carbon sequestration or abatement? The effect of rising carbon prices on the optimal portfolio of greenhouse-gas mitigation strategies. Journal of Environmental Economics and Management, 50(1), 59-81. doi: 10.1016/j.jeem.2004.09.002

van Kooten, G. C. (2009). Biological carbon sequestration and carbon trading re-visited. Climatic Change, 95(3), 449-463. doi: 10.1007/s10584-009-9572-8

van Kooten, G. C., \& de Vries, F. P. (2013). Carbon Offsets. In J. F. Shogren (Ed.), Encyclopedia of Energy, Natural Resource, and Environmental Economics (pp. 6-8): Elsevier

West, T. O., Marland, G., King, A. W., Post, W. M., Jain, A. K., \& Andrasko, K. (2004). Carbon Management Response Curves: Estimates of Temporal Soil Carbon 
Dynamics. Environmental Management, 33(4), 507-518. doi: 10.1007/s00267-0039108-3

West, T. O., \& Post, W. M. (2002). Soil Organic Carbon Sequestration Rates by Tillage and Crop Rotation. Soil Sci. Soc. Am. J., 66(6), 1930-1946. doi: 10.2136/sssaj2002.1930

Wigley, T., Clarke, L., Edmonds, J., Jacoby, H., Paltsev, S., Pitcher, H., et al. (2009). Uncertainties in climate stabilization. Climatic Change, 97(1), 85-121. doi: 10.1007/s10584-009-9585-3

Woodhams, F., Southwell, D., Bruce, S., Barnes, B., Appleton, H., Rickards, J., et al. (2012). The Carbon Farming Initiative: A proposed common practice framework for assessing additionality. Canberra: ABARES technical report 12.2. 